\title{
The relationship of Inhibitory Processes and Working Memory to Intelligence and Reading Skills in Children with Mild Intellectual Disabilities and Borderline Intelligence
}

\author{
Alevriadou Anastasia ${ }^{1}$, Rachanioti Eleni ${ }^{2}$ and Giaouri Stergiani ${ }^{3}$ \\ University of Western Macedonia, Greece ${ }^{1,2,3}$
}

\begin{abstract}
Research on intellectual functioning suggests that intelligence weaknesses could involve deficits in Executive functions. In addition, research on the reading skills of students with Intellectual Disabilities, due to unspecified etiology, is sparse. Thus, the purpose of our study was to investigate inhibitory processes and working memory as well as their relationship to different degrees of intellectual disability and reading attainment. It was conducted on a randomized sample including 20 school children in the age of 6-8, whose intelligence was evaluated with the Wechsler Intelligence Scale for Children. A modified version of a go/no go task was used to assess inhibition. Working Memory Rating Scale (WMRS) was administered for the assessment of the working memory and the "Test of Reading Difficulties in kindergarten and $1 \mathrm{st}-2^{\text {nd }}$ Elementary School" for the assessment of their reading performance. Results are analyzed in terms of deficits and strengths in children with mild intellectual disabilities and borderline intelligence. The predictive role of the working memory in both groups is also discussed.
\end{abstract}

Keywords: mild intellectual disabilities, borderline intelligence, inhibition, working memory, reading skills. 


\author{
21-23 December, 2018 in Berlin - Germany
}

\title{
Introduction
}

Whether EFs are impaired in children with Mild Intellectual Disabilities (MID) and Borderline Intelligence (BI) is not totally clear. Findings suggest developmental delays in the Efs of children with MID and BI (Van der Molen et al., 2007). Differences for inhibition performance and processing speed were also found, but less consistent across the tasks used to measure these aspects of Efs in children with MID and BI (Schuiringa et al., 2017).

Regarding reaction time and its relationship to $I Q$, studies have mainly reported conflicting results (Khodadadi et al., 2014). In particular, studies on individuals with ID have shown either a meaningful and negative correlation between reaction time and intelligence (Nissan et al., 2013) or no meaningful relationship (Bates \& Stough, 1998). Thus, it is concluded that the relationship between reaction time and IQ is too complicated and a significant correlation depends on various variables (Khodadadi et al., 2014).

Concerning working memory (the ability to hold and manipulate information with the aim of recalling it) in children with MID, research shows a developmental lag in this construct of the Efs, which is in line with their general intellectual ability (Schuchardt et al., 2010). Therefore, their performance in working memory components is roughly at the level of younger children matched on mental age (Schuchardt et al., 2010; Van der Molen et al., 2009). It should be noted that children with MID or BI show heterogeneous domain-specific effects on performance with working memory tasks (Van der Molen et al., 2007), which might as well be related to specific "structural" impairments affecting storage of verbal, visual, or spatial information (Jarrold \& Towse, 2006).

While students with ID, due to unspecified etiology, demonstrate skills in the field of literacy and a central aim of their education is the acquisition of reading and writing, research on their reading skills is sparse (Channell et al., 2013), which may be due to the heterogeneity of the group of children with ID, since their intelligence and language ranges from borderline to severe cases (Ratz \& Lenhard, 2013). Findings suggest that the combination of poor phonological representation and poor phonological output assembly makes decoding difficult for children with ID (Conners et al., 2001). Most of the studies conducted with children, adolescents or adults with ID with mixed or unspecified etiology found that phonological awareness was significantly related to word identification or non-word reading (Soltani \& Roslan, 2013; Wise et al., 2010).

This deficit of individuals with ID in the phonological store can be attributed to their working memory capacity and not to the accuracy of processing (Maehler \& 


\section{1-23 December, 2018 in Berlin - Germany}

Schuchardt, 2011). Nevertheless, previous research has shown that working memory performance of students with MID can be improved (Danielsson et al., 2015), as well as computerized cognitive training in children with MID leads to improved performance on non-trained tasks (Ottersen \& Grill, 2015). However, the evidence is weak for these positive outcomes generalizing to other cognitive skills, such as transfer to nonverbal or verbal ability, word decoding, reading comprehension or arithmetic.

Thus, our goal in the present study, which was conducted from September 2018 until November 2018, was to investigate intelligence and its relationship to inhibition, working memory as well as reading skills in children with MID and BI. The basic objectives of the study were: a) to investigate the correlation (if any) of the reaction time and working memory with the factors as assessed by the subtests of the Wechsler Intelligence Scale for Children battery (WISC-III) in both groups, b) to investigate the correlation (if any) of the reaction time and working memory with the WISC-III Intelligence Quotient (IQ), Verbal Intelligence (VI) and Performance Intelligence (PI) c) to investigate the correlation (if any) of the reaction time as well as working memory with the reading decoding, reading comprehension, phonological awareness and short - term memory as assessed by the subtests of the "Test of Reading Difficulties in kindergarten and 1st-2nd Elementary School" (Porpodas, 2007) and d) to investigate whether the IQ, reaction time and working memory variables (if any) can predict the reading variables.

\section{Participants}

\section{Methods}

The present study involved two groups of participants: 10 primary school children at the mean age of 7.2 years old, with $\mathrm{BI}$ (mean $\mathrm{IQ}=76.70$, s.d. $=4.373$ ) and 10 primary school children at the mean age of 7.4 years old, with BDI (mean IQ $=60.10$, s.d. = 4.725). The sex ratio in that group was approximately 1:1 (male: female). The children were evaluated by the Public Centre for Diagnosis and Support for Children with Special Educational Needs and Disability (Hellenic Ministry of Education, Research and Religious Affairs) in Kozani, Greece. None of the children had psychopathology or autism spectrum disorders. All attended inclusive settings.

\section{Measures}

a) A Greek version of the WISC-III (Georgas et al., 1997). It was administered by a licensed psychologist.

b) "Test of Reading Difficulties in kindergarten and 1st-2nd Elementary School" (Porpodas, 2007). It consists of nine subtests that evaluate four key areas of cognitive-language functions related to the reading process: 


\section{1-23 December, 2018 in Berlin - Germany}

- Reading decoding is divided into two sub-categories: a) reading syllables and reading pseudo-words

- Reading comprehension consists of: a) Reading sentences and selecting pictures and b) Reading and completing incomplete sentences.

- Phonological awareness consists of: a) Distinction of phonemes b) Segmentation of Pseudowords in phonemes and c) Deletion of phonemes

- Short-term memory consists of: a) Memory of sequential numbers and b) Pseudowords repetition

c) A Greek version of the Working Memory Rating Scale-WMRS (Alloway \& Gathercole, 2008). It is a behavioral rating scale developed for teachers to facilitate easy identification of children with working memory deficits. The WMRS consists of 22 items and provides a quick and efficient way for early identification of working memory problems that will impair learning.

d) Computerized version of a go/no go task

In order to assess simple reaction time, which refers to the time when the individual only reacts to a specific stimulus, such as when subjects must press a button on hearing a voice or seeing a visual stimulus, Psytoolkit platform (Stoet, 2017) was used to create a computerized version of a go/no go task. The go signal was an apple and the no-go signal was an orange. The student was instructed to press the space bar with the index finger of the preferred hand as fast as possible, when a Go signal would appear on-screen. When a No-Go signal appeared on-screen, the student had to inhibit response. Each signal appeared for $2000 \mathrm{~ms}$. A valid response window was set to $0-2000$ ms post stimulus onset. During the task, 8 trials and 20 go/no go signals were presented in a random order. GNG Inhibition was the mean simple reaction time difference between the congruent and incongruent trials.

\section{Procedure}

All participants were tested individually at their school in two 60 min sessions. The sessions took place in a quiet room. Potential ethical dilemmas were dealt with the official permission of the Principals of the schools that participated in the study, the informative cover letter and the consent form signed by the parents of the students. 


\section{1-23 December, 2018 in Berlin - Germany}

\section{Results}

The hypothesis of Normality was tested for all variables. In order to test whether there is a statistically significant difference between the two groups' performance, a oneway Analysis of Variance was used for those that follow a Normal distribution, whereas the non-parametric Mann-Whitney test was used for the remaining.

The results depicted (using a 0.05 significance level) statistically significant differences between the two groups' performance in the following subtests of the "Test of Reading Difficulties in kindergarten and 1st-2nd Elementary School" (Porpodas,2007) in favor of the BI group: Reading Syllables $(Z=-2,365, p=0,019 \leq 0.05)$, Reading Pseudowords $(Z=-2,825, p=0,004 \leq 0.05)$, Reading and Completing Sentences $(Z=-$ $3,480, p=0,000 \leq 0.05)$, Segmentation of Pseudowords into Phonemes $(Z=-2,180, p$ $=0,029 \leq 0.05)$ and Pseudowords Repetition $(Z=-2,037, p=0,043 \leq 0.05)$. There was no statistically significant difference between the two groups in Mean Reaction Time $[F(1,18)=0,579, p=0,456]$, Error Rate $(Z=-2,010, p=0,063)$ and Working Memory $(Z$ $=-0,926, p=0,393)$. It should be noted that both groups had low scores in Working Memory performance (in BI group: mean $=73,50$, s.d. $=1,515$ and in MID group: mean $=75,40$, s.d. $=0,618$ ) as it was assessed by the WMRS, with higher scores than the average standardized mean score 50 indicating deficits in working memory.

The relationship between the variables of WISC-III and the variables of the Test of Reading Difficulties as well as Mean Reaction Time, Error Rate and Working Memory was investigated in both groups, using Pearson correlation coefficient for those that follow a Normal distribution, whereas Spearman's rho was used for the remaining.

Regarding students with $\mathrm{BI}$, the results indicated positive correlations between Picture Arrangement and Reading Pseudowords $[r(10)=0,730, p=0,017 \leq 0,05]$ as well as Working Memory and Reading Pseudowords $[r(10)=0,738, p=0,015 \leq 0,05]$. Reading and Completing Incomplete sentences correlated with Verbal IQ [ $r(10)=$ $0,653, p=0,041 \leq 0,05]$, Performance IQ $[r(10)=0,770, p=0,009 \leq 0,05]$, Full Scale IQ $[r(10)=0,846, p=0,002 \leq 0,05]$ and Working Memory $[r(10)=0,634, p=0,049 \leq 0,05]$. A strong correlation was revealed between Working Memory and Segmentation of Pseudowords into Phonemes $[r(10)=0,859, p=0,001 \leq 0,05]$. In addition, Mean Reaction Time positively correlated with Working Memory $[r(10)=0,852, p=$ $0,002 \leq 0,05]$, but negatively correlated with Arithmetic $[r(10)=-0,693, p=$ $0,026 \leq 0,05]$. Reading Syllables correlated with Picture Arrangement $[r(10)=0,828, p$ $=0,003 \leq 0,05]$ and Object Assembly $[r(10)=0,709, p=0,022 \leq 0,05]$. Moreover, Deletion of Phonemes correlated with Picture Arrangement $[r(10)=0,797, p=$ $0,006 \leq 0,05]$, Object Assembly $[r(10)=0,652, p=0,041 \leq 0,05]$ and Digit Span $[r(10)=$ $0,740, p=0,014 \leq 0,05]$. Finally, Arithmetic correlated with Error Rate $[r(10)=0,751, p$ $=0,012 \leq 0,05]$. 


\section{SOCIAL SCIENCE, HUMANITIES \& EDUCATION}

\section{1-23 December, 2018 in Berlin - Germany}

In respect of the students with MID, the results indicated positive correlations between Reading Sentences and Selecting Pictures and Verbal IQ $[r(10)=0,633, p=$ $0,049 \leq 0,05]$, as well as Full Scale IQ $[r(10)=0,632, p=0,050 \leq 0,05]$. Moreover, Error Rate correlated with Arithmetic $[r(10)=0,634, p=0,049 \leq 0,05]$, as well as with Digit Span $[r(10)=0,797, p=0,006 \leq 0,05]$.

In order to examine a causal effect relationship between the variables of the "Test of Reading Difficulties in kindergarten and 1st-2nd Elementary School" (Porpodas,2007) and Verbal IQ, Performance IQ, Full scale IQ, Mean Reaction time, Error Rate and Working Memory, General Linear Models (GLMs) were applied (Taylor, 2011), having as a factor the variable intelligence and as covariates the Verbal IQ, Performance IQ, Full scale IQ, Mean Reaction time, Error rate and Working Memory.

The model was tested in terms of homoscedasticity of the independent variables. Levene's tests were computed in order to examine the assumption of equal variances, since our data came from a non-normal distribution. It was found that null hypothesis of homoscedasticity cannot be rejected $[F(1,18)=0,168, p=0,687 \geq 0,05]$ for Reading Pseudowords and Segmentation of Pseudowords into Phonemes $[F(1,18)=0,168, p=$ $0,686 \geq 0,05$ ] respectively.

Table 1.1 shows the means and standard deviations of the students' performance on Reading Pseudowords.

The results of the tests of between-subjects effects (Tables 1.2,1.3) revealed (at a significance level of $10 \%)$ that Working Memory can be a statistical important predictor for Reading Pseudowords $[F(1,12)=3,99, p=0,069]$. Adjusted R Squared $(0,482)$ shows the percentage of variability of the dependent variable Reading Pseudowords explained by the specific model.

Table 1.1: Means and Standard Deviations of the Students' Performance on Reading Pseudowords

\begin{tabular}{|l|r|r|r|}
\hline \multicolumn{4}{|c|}{ Descriptive Statistics } \\
\hline Dependent Variable: READING PSEUDOWORDS \\
\hline Grouping2 & \multicolumn{1}{|c|}{ Mean } & Std. Deviation & $\mathrm{N}$ \\
\hline Mild Intellectual disability & 3,90 & 4,202 & 10 \\
\hline Borderline Intelligence & 11,70 & 5,813 & 10 \\
\hline Total & 7,80 & 6,354 & 20 \\
\hline
\end{tabular}


International Conference on

\section{SOCIAL SCIENCE, HUMANITIES \& EDUCATION}

\section{1-23 December, 2018 in Berlin - Germany}

Table 1.2: Tests of Between-Subjects Effects - Dependent Variable: Reading Pseudowords

\begin{tabular}{|c|c|c|c|c|c|}
\hline \multicolumn{6}{|c|}{ Dependent Variable: READING PSEUDOWORDS } \\
\hline Source & Type III Sum of Squares & df & Mean Square & $\mathrm{F}$ & Sig. \\
\hline Corrected Model & $516,017^{a}$ & 7 & 73,717 & 3,522 & 0,027 \\
\hline Intercept & 17,342 & 1 & 17,342 & 0,828 & 0,381 \\
\hline VERBAL IQ & 1,713 & 1 & 1,713 & 0,082 & 0,780 \\
\hline PERFORMANCE IQ & 10,668 & 1 & 10,668 & 0,510 & 0,489 \\
\hline FULL SCALE IQ & 4,882 & 1 & 4,882 & 0,233 & 0,638 \\
\hline MEAN REACTION TIME & 3,017 & 1 & 3,017 & 0,144 & 0,711 \\
\hline ERROR RATE & 16,417 & 1 & 16,417 & 0,784 & 0,393 \\
\hline WORKING MEMORY & 83,520 & 1 & 83,520 & 3,990 & 0,069 \\
\hline Grouping2 & 45,326 & 1 & 45,326 & 2,165 & 0,167 \\
\hline Error & 251,183 & 12 & 20,932 & & \\
\hline Total & 1984,000 & 20 & & & \\
\hline Corrected Total & 767,200 & 19 & & & \\
\hline
\end{tabular}

a. R Squared $=.673$ (Adjusted R Squared $=.482$ ) 


\section{SOCIAL SCIENCE, HUMANITIES \& EDUCATION}

\section{1-23 December, 2018 in Berlin - Germany}

Table 1.3: Parameter Estimates - Dependent Variable: Reading Pseudowords

\begin{tabular}{|c|c|c|c|c|c|c|}
\hline \multicolumn{7}{|c|}{ Parameter Estimates } \\
\hline \multicolumn{7}{|c|}{ Dependent Variable: READING PSEUDOWORDS } \\
\hline \multirow[b]{2}{*}{ Parameter } & \multirow[b]{2}{*}{ B } & \multirow[b]{2}{*}{ Std. Error } & \multirow[b]{2}{*}{$\mathrm{t}$} & \multirow[b]{2}{*}{ Sig. } & \multicolumn{2}{|c|}{ 90\% Confidence Interval } \\
\hline & & & & & Lower Bound & Upper Bound \\
\hline Intercept & 56,279 & 58,594 & 0,960 & 0,356 & $-48,153$ & 160,710 \\
\hline VERBAL IQ & 0,704 & 2,462 & 0,286 & 0,780 & $-3,684$ & 5,093 \\
\hline PERFORMANCE IQ & 1,546 & 2,166 & 0,714 & 0,489 & $-2,314$ & 5,407 \\
\hline FULL SCALE IQ & $-2,007$ & 4,156 & $-0,483$ & 0,638 & $-9,414$ & 5,400 \\
\hline $\begin{array}{l}\text { MEAN REACTION } \\
\text { TIME }\end{array}$ & $-0,003$ & 0,008 & $-0,380$ & 0,711 & $-0,018$ & 0,012 \\
\hline ERROR RATE & $-0,324$ & 0,366 & $-0,886$ & 0,393 & $-0,976$ & 0,328 \\
\hline WORKING MEMORY & $-0,849$ & 0,425 & $-1,998$ & 0,069 & $-1,607$ & $-0,092$ \\
\hline [Grouping2=1] & $-6,804$ & 4,624 & $-1,472$ & 0,167 & $-15,046$ & 1,437 \\
\hline [Grouping2=2] & $0^{\mathrm{a}}$ & & & & & \\
\hline
\end{tabular}

Table 2.1 shows the means and standard deviations of the students' performance on Segmentation of Pseudowords into Phonemes. Similarly, Working Memory can be a statistical important predictor for Segmentation of Pseudowords into Phonemes $[F$ $(1,12)=7,09, p=0,021$ ]. Adjusted $\mathrm{R}$ Squared $(0,490)$ shows the percentage of variability of the dependent variable Segmentation of Pseudowords into Phonemes explained by the specific model (Tables 2.2, 2.3). 
International Conference on

\section{SOCIAL SCIENCE, HUMANITIES \& EDUCATION}

\section{1-23 December, 2018 in Berlin - Germany}

Table 2.1: Means and Standard Deviations of the Students' Performance on Segmentation of Pseudowords into Phonemes

\begin{tabular}{|l|r|r|r|}
\hline \multicolumn{4}{|c|}{ Descriptive Statistics } \\
\hline Dependent Variable: SEGMENTATION OF PSEUDOWORDS INTO PHONEMES \\
\hline Grouping2 & Mean & Std. Deviation & $\mathrm{N}$ \\
\hline Mild Intellectual Disability & 3,20 & 3,393 & 10 \\
\hline Borderline Intelligence & 7,90 & 5,216 & 10 \\
\hline Total & 5,55 & 4,915 & 20 \\
\hline
\end{tabular}

Table 2.2: Tests of Between-Subjects Effects - Dependent Variable: Segmentation of Pseudowords into Phonemes

\begin{tabular}{|c|c|c|c|c|c|}
\hline Source & $\begin{array}{l}\text { Type } \\
\text { Sum of } \\
\text { Squares }\end{array}$ & df & $\begin{array}{l}\text { Mean } \\
\text { Square }\end{array}$ & $\mathrm{F}$ & Sig. \\
\hline Corrected Model & $311,171^{a}$ & 7 & 44,453 & 3,610 & 0,025 \\
\hline Intercept & 4,688 & 1 & 4,688 & 0,381 & 0,549 \\
\hline VERBAL IQ & 5,526 & 1 & 5,526 & 0,449 & 0,516 \\
\hline PERFORMANCE IQ & 9,226 & 1 & 9,226 & 0,749 & 0,404 \\
\hline FULL SCALE IQ & 6,094 & 1 & 6,094 & 0,495 & 0,495 \\
\hline $\begin{array}{l}\text { MEAN REACTION } \\
\text { TIME }\end{array}$ & 0,277 & 1 & 0,277 & 0,023 & 0,883 \\
\hline ERROR RATE & 0,003 & 1 & 0,003 & 0,000 & 0,987 \\
\hline $\begin{array}{l}\text { WORKING } \\
\text { MEMORY }\end{array}$ & 87,423 & 1 & 87,423 & 7,099 & 0,021 \\
\hline Grouping2 & 0,951 & 1 & 0,951 & 0,077 & 0,786 \\
\hline Error & 147,779 & 12 & 12,315 & & \\
\hline Total & 1075,000 & 20 & & & \\
\hline Corrected Total & 458,950 & 19 & & & \\
\hline
\end{tabular}

a. $R$ Squared $=.678$ (Adjusted $R$ Squared $=.490$ ) 


\title{
SOCIAL SCIENCE, HUMANITIES \& EDUCATION
}

\author{
21-23 December, 2018 in Berlin - Germany
}

Table 2.3: Parameter Estimates - Dependent Variable: Segmentation of Pseudowords into Phonemes

\begin{tabular}{|c|c|c|c|c|c|c|}
\hline \multicolumn{7}{|c|}{ Dependent Variable: SEGMENTATION OF PSEUDOWORDS INTO PHONEMES } \\
\hline \multirow[b]{3}{*}{ Parameter } & \multirow[b]{3}{*}{ B } & \multirow[b]{3}{*}{ Std. Error } & \multirow[b]{3}{*}{$\mathrm{t}$} & \multirow[b]{3}{*}{ Sig. } & \multicolumn{2}{|c|}{$\begin{array}{c}90 \% \text { Confidence } \\
\text { Interval }\end{array}$} \\
\hline & & & & & Lower & Lower \\
\hline & & & & & Bound & Bound \\
\hline Intercept & 27,987 & 44,943 & 0,623 & 0,545 & $-52,115$ & 108,08 \\
\hline & & & & & & 9 \\
\hline VERBAL IQ & 1,265 & 1,889 & 0,670 & 0,516 & $-2,101$ & 4,632 \\
\hline PERFORMANCE IQ & 1,438 & 1,661 & 0,866 & 0,404 & $-1,523$ & 4,399 \\
\hline FULL SCALE IQ & $-2,242$ & 3,188 & $-0,703$ & 0,495 & $-7,923$ & 3,439 \\
\hline MEAN REACTION TIME & 0,001 & 0,006 & 0,150 & 0,883 & $-0,010$ & 0,012 \\
\hline ERROR RATE & $-0,005$ & 0,280 & $-0,016$ & 0,987 & $-0,504$ & 0,495 \\
\hline WORKING MEMORY & $-0,869$ & 0,326 & $-2,664$ & 0,021 & $-1,450$ & $-0,288$ \\
\hline [Grouping2=1] & $-0,986$ & 3,547 & $-0,278$ & 0,786 & $-7,307$ & 5,336 \\
\hline [Grouping2=2] & $0^{\mathrm{a}}$ & . & . & . & . & . \\
\hline
\end{tabular}

a. This parameter is set to zero because it is redundant.

\section{Discussion}

In the present study, intelligence and its relationship to inhibition, working memory as well as reading skills in children with MID and BI was investigated. Moreover, an effort to determine which of the Efs (if any) can predict the reading factors was attempted.

Students with MID and students with BI were found not to differ statistically significant either in Reaction Time or in Working Memory tasks. In addition, Full scale IQ does not correlate with Mean Reaction time and Working Memory in both groups. Our results are consistent with other previous reports (Bates \& Stough, 1998; Jauregi et al., 2007).

In general, the relationship between the Efs and IQ in children with $\mathrm{BI}$ and MID is too complicated and revealing a significant correlation depends on various factors, such as developmental delay in working memory, which is in line with their general intellectual ability (Schuchardt et al., 2010). Moreover, specific "structural" impairments affecting storage of verbal, visual, or spatial information (Jarrold \& Towse, 2006; Lanfranchi et al., 2004) contribute to the heterogeneity of this population. Besides, it should be noted that both groups received low scores in WMRS, 


\title{
International Conference on SOCIAL SCIENCE, HUMANITIES \& EDUCATION
}

\author{
21-23 December, 2018 in Berlin - Germany
}

which is in accordance with findings from previous reports which have shown that working memory deficits increase in inverse proportion to IQ (Schuchardt et al., 2010; Van der Molen et al., 2009).

The analysis of the data, with respect to the relationship of intelligence with the reading variables as well as Mean Reaction Time, Error Rate and Working Memory revealed significant correlations, which are also in line with those of previous studies. Arithmetic correlated with Error Rate in both groups (Clark et al., 2010). Digit Span positively correlated with Reading Pseudowords and the Deletion of Phonemes in BI group (Mayes et al., 2009). Moreover, Working Memory correlated with Reading Pseudowords, Segmentation of Pseudowords into Phonemes and Mean Reaction Time (Channell et al., 2013).

It is worth mentioning that Object Assembly and Picture Arrangement, both assessing nonlinguistic reasoning ability, were found to correlate with Reading Pseudowords and Reading Syllables in Bl group. It seems that when cognitive impairments are apparent, the development of reading skills is affected not only via linguistic skills but also via nonlinguistic reasoning ability, with the latter most likely explained by the fact that it represents general intelligence capacity (van Wingerden et al., 2018).

The key finding in our study is that Working Memory appears to have a predictive power in relation to reading abilities in both groups, more specifically to Phonological Awareness and Reading Decoding. In general, it seems that working memory deficits themselves lie at the heart of some of the learning difficulties experienced by such individuals (see also Jarrold \& Brock, 2012).

\section{Conclusion}

Considering the aforementioned findings and the results of previous studies showing that there is a developmental lag in working memory as well as "structural" deficiencies affecting storage of verbal, visual, or spatial information, which are in line with their general intellectual ability, we suggest implementing working memory training programmes adapted to students' abilities with MID and $\mathrm{BI}$, by taking into consideration their neurobiological limitations and reducing the cognitive load. Besides, research has shown that the working memory of children with ID can be improved (Danielsson et al., 2015). With regard to their reading skills, similar approaches should be applied, aiming to reduce the amount of phonological information to be held in working memory, thus leaving cognitive reserve for reading decoding. 


\title{
International Conference on SOCIAL SCIENCE, HUMANITIES \& EDUCATION
}

\author{
21-23 December, 2018 in Berlin - Germany
}

Given the limited number of the target population, the results of the present study cannot be generalized. A larger sample of both BI and MID students should be included in a further study, in order to comparatively investigate the Efs and their relationship with reading skills using a variety of cognitive tools.

\section{References}

[1] Alloway, T. P., \& Gathercole, S. E. (2008). Working Memory Rating Scale (WMRS): Manual. London: Pearson Education.

[2] .Bates, T., \& Stough, C. (1998). Improved reaction time method, information processing speed, and intelligence, Intelligence, vol. 26, pp. 53-62.

[3] Channell, M. M., Loveall, S. J., \& Conners, F. A. (2013). Strengths and weaknesses in reading skills of youth with intellectual disabilities, Research in Developmental Disabilities, vol. 34, pp. 776-787.

[4] Clark, C. A., Pritchard, V. E., \& Woodward, L. J. (2010). Preschool executive functioning abilities predict early mathematics achievement. Developmental Psychology, vol. 46(5), pp. 1176-1191.

[5] Conners, F. A., Atwell, J. A., Rosenquist, C. J., \& Sligh, A. C. (2001). Abilities underlying decoding differences in children with intellectual disability, Journal of Intellectual Disability Research, vol. 45, pp. 292-299.

[6] Danielsson, H., Zottarel, V., Palmqvist, L., \& Lanfranchi, S. (2015). The effectiveness of working memory training with individuals with intellectual disabilities-a meta-analytic review, Frontiers in Psychology, vol. 6, pp. 48-57

[7] Duncan, J., Burgess, P., \& Emslie, H. (1995). Fluid intelligence after frontal lobe lesions, Neuropsychologia, vol. 33, pp. 261-268.

[8] Friedman, N. P., Miyake, A., Corley, R. P., Young, S. E., DeFries, J. C., \& Hewitt, J. K. (2006). Not all executive functions are related to intelligence, Psychological Science, vol. 17, pp. 172-179.

[9] Goldstein, S., \& Naglieri, J. A. (Eds.). (2013). Handbook of Executive Functioning. New York, NY: Springer Science \& Business Media.

[10] Jarrold, C., \& Brock, J. (2012). Short term memory and working memory in mental retardation. In J.A. Burack, R.B. Hodapp, G. Iarocci, \& E. Zigler (Eds.), The Oxford Handbook of Intellectual Disability and Development, pp. 109-124. Oxford, NY: Oxford University Press.

[11] Jarrold, C., \& Towse, J. N. (2006). Individual differences in working memory, Neuroscience, vol. 139, pp. 39-50.

[12] Jauregi, J., Arias, C., Vegas, O., Alen, F., Martinez, S., Copet, P., \& Thuilleaux, D. (2007). A neuropsychological assessment of frontal cognitive functions in Prader-Willi syndrome, Journal of Intellectual Disability Research, vol. 51, pp. 350-365. 


\section{1-23 December, 2018 in Berlin - Germany}

[13] Khodadadi, M., Ahmadi, K., Sahrai, H., Abadi, E. A., \& Yadolahi, S. (2014). Relationship between intelligence and reaction time: A review study, International Journal of Medical Reviews, vol. 1(2), pp.63-69

[14] Maehler, C., \& Schuchardt, K. (2009). Working memory functioning in children with learning disabilities: does intelligence make a difference? Journal of Intellectual Disability Research, vol. 53, pp. 3-10.

[15] Maehler, C., \& Schuchardt, K. (2011). Working memory in children with learning disabilities: Rethinking the criterion of discrepancy, International Journal of Disability, Development and Education, vol.58, pp. 5-17.

[16] Mayes, S. D., Calhoun, S. L., Bixler, E. O., \& Zimmerman, D. N. (2009). IQ and neuropsychological predictors of academic achievement, Learning and Individual Differences, vol.19, pp.238-241.

[17] Nissan, J., Liewald, D., \& Deary, I. J. (2013). Reaction time and intelligence: Comparing associations based on two response modes, Intelligence, vol. 41, pp. 622-630.

[18] Ottersen, J., \& Grill, K. M. (2015). Benefits of extending and adjusting the level of difficulty on computerized cognitive training for children with intellectual disabilities, Frontiers in Psychology, vol.6, pp.58-68.

[19] Porpodas, K. (2007). Detection test of Reading Difficulties. Athens: Ypepth, Epeaek (in Greek).

[20] Ratz, C., \& Lenhard, W. (2013). Reading skills among students with intellectual disabilities, Research in Developmental Disabilities, vol. 34, pp. 1740-1748.

[21] Rowe, J., Lavender, A., \& Turk, V. (2006). Cognitive executive function in Down's syndrome, British Journal of Clinical Psychology, vol. 45, pp. 5-17.

[22] Schuchardt, K., Gebhardt, M., \& Mäehler, C. (2010). Working memory functions in children with different degrees of intellectual disability, Journal of Intellectual Disability Research, vol. 54, pp. 346-353.

[23] Schuiringa, H., van Nieuwenhuijzen, M., Orobio de Castro, B., \& Matthys, W. (2017). Executive functions and processing speed in children with mild to borderline intellectual disabilities and externalizing behavior problems, Child Neuropsychology, vol. 23, pp. 442-462.

[24] Soltani, A., \& Roslan, S. (2013). Contributions of phonological awareness, phonological short-term memory, and rapid automated naming, toward decoding ability in students with mild intellectual disability, Research in Developmental Disabilities, vol. 34, pp. 1090-1099.

[25] Stoet, G. (2017). PsyToolkit: A novel web-based method for running online questionnaires and reaction-time experiments, Teaching of Psychology, vol. 44, pp. 24-31.

[26] Taylor, A. (2011). Using the GLM Procedure in SPSS. Macquarie: Macquarie University Press.

[27] Van der Molen, M. J., Van Luit, J. E., Jongmans, M. J., \& Van der Molen, M. W. (2007). Verbal working memory in children with mild intellectual disabilities, Journal of Intellectual Disability Research, vol. 51, pp. 162-169. 


\section{1-23 December, 2018 in Berlin - Germany}

[28] Van der Molen, M. J., Van Luit, J. E., Jongmans, M. J., \& Van der Molen, M. W. (2009). Memory profiles in children with mild intellectual disabilities: Strengths and weaknesses, Research in Developmental Disabilities, vol. 30, pp. 1237-1247.

[29] van Wingerden, E., Segers, E., van Balkom, H., \& Verhoeven, L. (2018). Cognitive constraints on the simple view of reading: A longitudinal study in children with intellectual disabilities, Scientific Studies of Reading, vol. 22, pp. 321-334.

[30] Georgas, D.D., Paraskevopoulos, I.N., Bezevegis, H.G., \& Giannitsas, N.D. (1997). Greek Version of the Wechsler Intelligence Scale for Children, WISCIII. Athens: Ellinika Grammata.

[31] Wise, J. C., Sevcik, R. A., Romski, M., \& Morris, R. D. (2010). The relationship between phonological processing skills and word and nonword identification performance in children with mild intellectual disabilities, Research in Developmental Disabilities, vol. 31, pp. 1170-1175. 